\title{
NEW LIGHT-SENSITIVE POSITIVE-WORKING THICK RESIST MATERIALS FOR VARIOUS ELECTRONIC APPLICATIONS $\dagger$
}

\author{
H. RUCKERT \\ Kalle Niederlassung, der Hoechst AG, Wiesbaden, West Germany
}

(Received June 30, 1979)

\begin{abstract}
Two different systems of light-sensitive resist materials precoated on carrier foils and their potential applications for thickfilm-technology and high quality printed circuits are described. In addition to $25 \mu \mathrm{m}$ diazo screen printing film already accepted in this field, new experimental films up to $70 \mu \mathrm{m}$ thickness can be provided. They show excellent shelf-life and can be transferred to the screen and developed after exposure simply with water. The second system is a $12 \mu \mathrm{m}$ positive dry film resist based on the same chemistry as all positive liquid resists. After lamination to a substrate it can be exposed directly on the resist. It gives better resolution than negative dry film resists and offers a potential for multiple exposure. Thicker positive dry films are possible using a new positive system without diazo compounds.
\end{abstract}

\section{DIAZO-PRESENSITIZED SILK-SCREEN FILM}

The first section of this paper deals with the progress in diazo-presensitized silk-screen film. ${ }^{1}$ This positive working screen-printing process is not only used to print inks on paper or many other substrates in the field of graphic applications. When we introduced the material to the market in 1974 as screen printing film S 25, distributed also under the designation Azocol Combicoat ${ }^{\circledR}$ together with Azocol $S^{\circledR}$ by Kissel and Wolf, we were also aware of its potential applications in the field of printed circuits. Meanwhile, it is widely used not only for simple printed circuit boards, but due to improved resolution and edge acuity also for applications, where formerly liquid or dry film resists were often used. Furthermore, in thickfilm technology such direct stencils from diazo coatings are used for printing of resistor, conductor, dielectric and other screen-printable pastes.

Besides photo-etched metal stencils or those made by the methods of electroforming, screen printing in this field can be accomplished preferably using steel or polyester screens. These are coated, exposed and developed using negative working resist materials like bichromate sensitized emulsions or films, photopolymer resist materials or diazo-sensitized or sensitizable lacquers or foils.

$\dagger$ To Prof. Dr. R. Sammet on the occasion of his 60 th birthday.
Our diazo film is the first presensitized direct screen printing film. It has all the known advantages of presensitized diazo printing plates and foils in graphic industry. It is manufactured by coating a $36 \mu \mathrm{m}$ polyester film base with a special diazo screen emulsion, is usually sold in roll form and can be used to prepare a stencil on almost any fabric of varying type and size.

In the simplest case the film is transferred to the contact side of the screen fabric only by wetting with water, pressing the screen onto the coating (the film mounted on a flat surface), and drying. To get a better bond on the tissue, the other method of wetting the screen with the corresponding aqueous diazo screen printing emulsion or a diluted solution of it is used. Thus the hydrophilic light-sensitive layer of this screen printing film is pressed by wiper or roller upon the coated screen. After drying the supporting film is stripped off and the coating is exposed to UV-light in direct contact with a positive line original. On exposure the diazo-compound is decomposed, and the layer is thus crosslinked and bonded to the fabric. To remove the unexposed areas, the coated screen is simply sprayed with water and after drying it is ready for printing. The printing side of the screen shows optimum equalization of the structure of the fabric compared to emulsion coated stencil screens from Azocol $S^{\circledR}$ or other stencil screens for fine-line printing. ${ }^{2}$

Because of its excellent quality this stencil is able to withstand the chemical attack of commercial 
printing inks and pastes and shows good durability against the mechanical wear caused by the squeegee. Due to the sharp meshcrossing contours and high resolving power and the smooth printing surface of the stencil, the prints show fine-detail reproduction. This compares well with the results obtained formerly with indirect stencils while the printing runs are as long as those obtained with direct stencils. In addition to these results, there is the advantage of ease of processing and the good shelf-life quality of at least one year under normal conditions proved during the last four years.

For thickfilm technology the $25 \mu \mathrm{m}$ screen printing film is not of sufficient thickness. Customers have already attempted to double the layer. With some skill this may be possible. These facts and the experience of the recent years encourages us to present light-sensitive precoated screen print foil up to $70 \mu \mathrm{m}$ thickness. Test material of these experimental 40 to $70 \mu \mathrm{m}$ thick films can be provided. We plan to offer screen print films of that thickness, which finds the broadest acceptance in the market.

Processing of these materials (Combicoat Ultra) is nearly the same as the afore-mentioned for the normal $25 \mu \mathrm{m}$ version of S 25 (Azocol Combicoat) for printed circuit boards. Exposure and development of the thicker films need additional time, depending on the light source and the developing conditions. Under optimized processing conditions of the screen pretreatment, film transfer to the screen, drying, exposure and development, we can offer an opportunity for improved thickfilm screen printing.

\section{POSITIVE DRY FILM RESISTS}

Whereas this diazo-presensitized film is used for applying either inks, lacquers or pastes (which after drying are resistant to etching, plating or other conditions) to substrates by screen-printing, the second section of this paper concerns positive dry film resists. Such material, similar to negative dry film resists, is coated by lamination to the substrate and exposed and developed there. The differences and similarities are obvious. Using the same transparency for exposure, instead of getting numerous screen prints from one stencil copy, many single copies are made directly onto the substrate using positive dry film resists.

Positive working dry film resist is a newly developed material. Until now, besides screen printing, negative and positive liquid resists, there are only negative dry film resists being marketed. The challenge in this field was to find a compromise between the advantageous features of positive liquid resists, i.e. Shipley AZ-resist ${ }^{\circledR} \dagger$ layers and the advantages of coating substrates by laminating like common negative dry resists. Several announcements and attempts during recent years indicate the difficulties to be overcome. Meanwhile, a $12 \mu \mathrm{m}$ thick diazopositive dry resist is available from Kalle for testing. It is furnished in rolls and consists of a blue-violet resist layer sandwiched between a $25 \mu \mathrm{m}$ polyester carrier and polyolefin protective film. Lamination and aqueous-alkaline development are carried out as usual. In contrast to negative dry resists, where exposure has to be carried out through the carrier foil, this positive dry resist can be exposed directly after pulling off the release carrier.

One may ask the question, what are the advantages and reasons for a positive dry film resist, considering also the aforementioned progress in screen-printing and the existing negative dry film resists of both solvent and alkaline-water development type.

Some special features of these uniform precoated positive dry film resists are as follows. Because it is positive working, it can be applied where positive liquid resists have been used in thicker layers, which usually are coated with difficulty using roller coater machines. In addition to dry film processing, positive dry film like positive liquid resist offers water-alkaline development and excellent resolution better than that attainable with negative dry film resists. We say that lines can be resolved as small as the resist is thick. It is agreed that this $12 \mu \mathrm{m}$ diazo positive dry resist can resolve $15 \mu \mathrm{m}$ lines. In one application even the close spacing of lines usually $20-40 \mu \mathrm{m}$ is possible down to $5 \mu \mathrm{m}$ width, which can be plated with $3 \mu \mathrm{m}$ gold giving lines of $3 \times 5 \mu \mathrm{m}$ profile. We recommend spray development of the exposed resist. It shows good contrast exposure and development.

Furthermore, positive dry film offers good resistance to many commonly used etchants and plating solutions and has a shelf-life of at least 9 months at room temperature. As a positive resist it has potential for multiple exposure, development and processing; for instance for gold-plating contacts after a second exposure and development of the still lightsensitive layer. One customer also uses a second $12 \mu \mathrm{m}$

$\dagger \mathrm{AZ}{ }^{\circledR}$ Photoresists, manufactured by Azoplate, Division of American Hoechst Corporation and KALLE, Niederlassung der Hoechst AG, distributed by Shipley. 
positive dry resist lamination after the etching and/or plating steps with the first coating. After the final lithographic procedures the remaining resist layer is heated for $10 \mathrm{~min}$. up to $240^{\circ} \mathrm{C}$, becoming an integral and permanent compound of the circuitboard and protecting it with good insulating properties. The dielectric constants are between 3-7, depending on the treatment of the positive dry resist layer.

The material can be stripped by the same methods normally employed for positive liquid resists without flakes and redeposits. Depending on the etching or plating conditions to be used, it may be desirable to improve chemical resistance and adhesion by post baking, similar to the application of positive liquid resists in microelectronics.

On this diazo-basis it is impossible to formulate much thicker positive dry resists, which have exposure times comparable to those of negative dry resists. In contrast to the photo-induced radical polymerisation of negative dry resists, the lightsensitivity of positivediazo coatings decreases rapidly with increasing coating thickness. To overcome this disadvantage for several applications of positive working light-sensitive materials, a preparative organic chemistry research program was initiated. The result is a new positive system without diazo-compounds. In the last section of this paper its application for a new positive dry resist generation is described.

\section{NON-DIAZO BASED POSITIVE RESIST}

Its main properties are high light-sensitivity and resolution, improved adhesion to various substrates, resistance to etchants and plating solutions and good insulation properties. In addition, to these superior properties of the newly developed photo degrading dry resist layers compared to the aforementioned diazo dry resist coatings and compared to negative dry resist layers, the following details may be mentioned.

Exposure times are approximately $5-8$ times shorter than for positive-diazo coatings of comparable thickness. Resist layers up to $100 \mu \mathrm{m}$ can be spraydeveloped within 3-5 minutes. Another feature of both our positive dry resists is the fact that the wanted thickness can be additively reached by double or multiple lamination of the thinner resist types. The high lightsensitivity of the new material enables the user to expose for instance stepwise coated $100 \mu \mathrm{m}$ layers in approximately the same time as $12 \mu \mathrm{m}$ positive diazo resist coatings. We hope to get feedback from hybrid electronic industry as to which thickness might be of most interest.

The resolution of fine lines is not limited by the alkaline water and non-swellable developing conditions. It depends upon the thickness of the resist and its adhesion to the substrate. Since the new system gives relatively less brittle positive coatings than positive diazo coatings and also no nitrogen bubbles can evolve in the exposed areas, both adhesion and resolution and edge acuity are excellent. Until now we have tested these properties not only on copper clads, but also on glass, chromium, nickel and gold surfaces and also lamination over non-planar structures. We are also wondering which requirements in this field are of most interest.

Etching, plating, post-baking and the stripping properties of this new experimental positive dry resist are similar to the diazo version. Due to its higher light-sensitivity it also has potential for a second exposure, development and processing of thick layers, for instance $50 \mu \mathrm{m}$. Finally, insulation properties of positive dry resists were examined. They depend upon the thickness of the layer, its thermal treatment and whether they are exposed or unexposed. For instance, post-exposure increases the dielectric values. Details will be subject to further research and development, when the most interesting applications and processing conditions are elucidated. We are sure that such coatings up to $100 \mu \mathrm{m}$ thickness should possess potential applications in various electronic and hybrid micro-electronic fields.

\section{REFERENCES}

1. H. Ruckert, Diazo-presensitized Silkscreen Film, $J$. Photogr. Sci. 22, 2 (1974) 104-106

2. S. G. Stalnecker, Stencil Screens for Fine-Line Printing. Proc. European Hybrid Micro-Electronics Conference 1979, Ghent 507-516. 

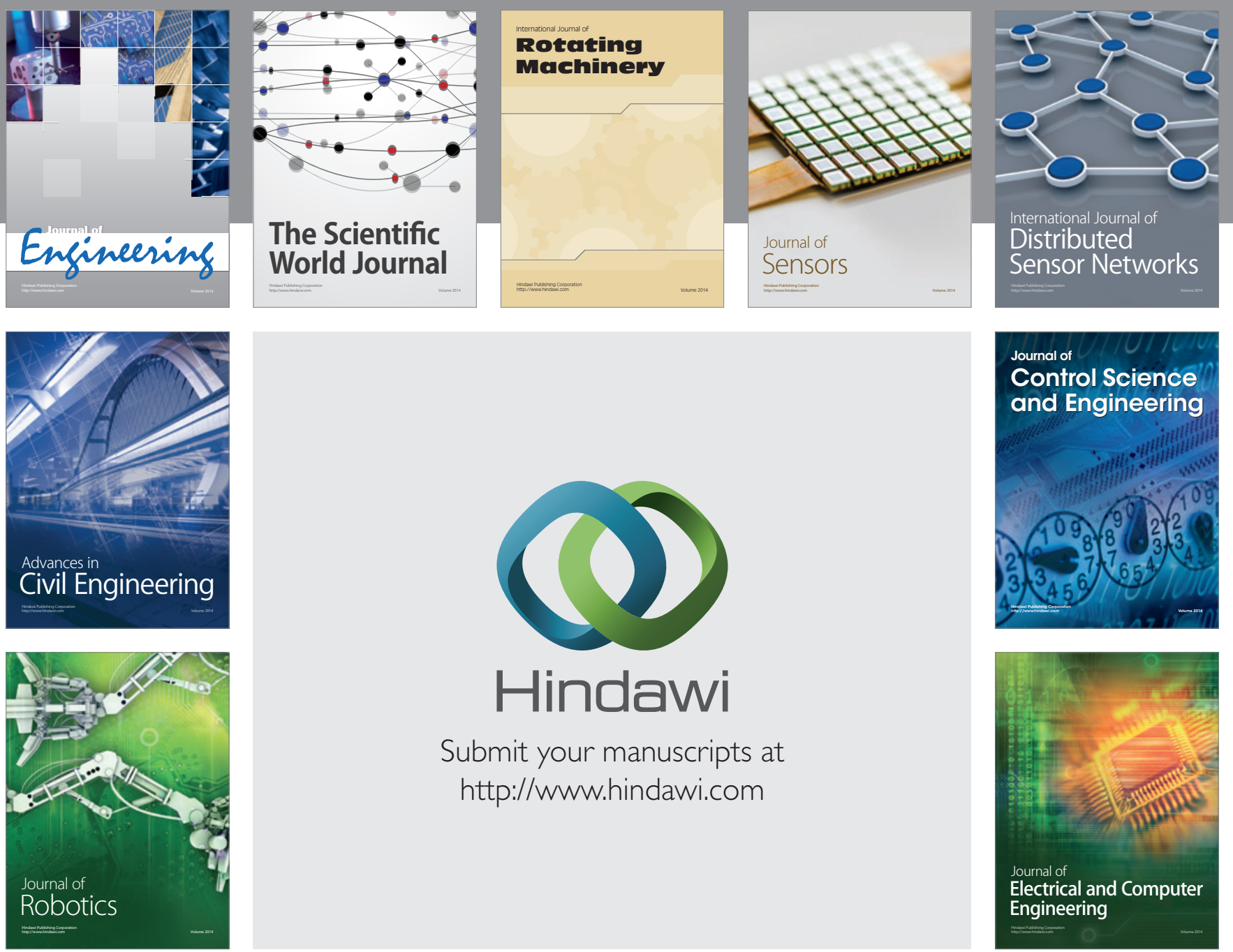

Submit your manuscripts at

http://www.hindawi.com
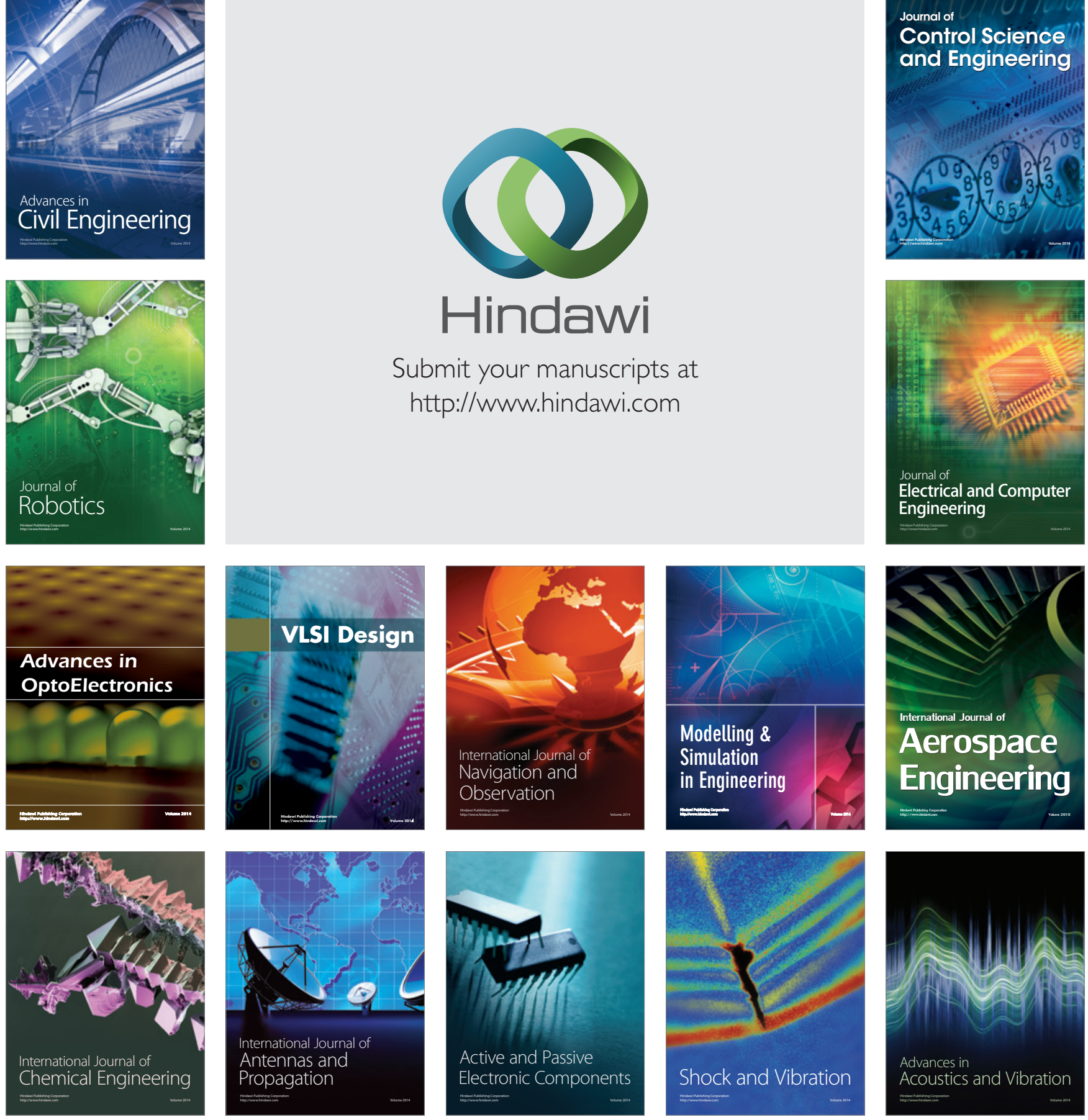